availed myself of the plentiful supply of material at my disposal. This investigation has, I venture to advance, established not only that visceral musele fibres do exist in the walls of the venous sinuses, but that their morbid changes are responsible for the form of vascular hypertrophy which I have ventured to call "turbinal varix."

Taviton-street, Gordon-square, W.C.

\section{CASES OF LIVER AND GALL-DUCT SURGERY. ${ }^{1}$}

BY JOHN D. MALCOLM, M.B., C.M., F.R.C.S. Edin., SURGEON TO THE SAMARITAN FREE HOSPITAT.

IN this paper I propose to relate in detail the histories of all the cates of disease of the liver or of the gall-ducts on which I have operated. The cases consist of three in which exploratory incisions were made, two operated on for hydatids, and three in which gall-stones were extracted. The three patients on whom I performed exploratory operations died from the progress of diseases which it was impossible to cure by surgical means, but the operations did not, directly or indirectly, bring about or even hasten the fatal results. The other patients are alive now.

CASE 1. Exploration; nature of disease not discovered.The first of the exploratory operations was performed on a woman forty-five years of age, whose family history gave no assistance in diagnosis. She said that a soft tumour had been taken out of her lower jaw eighteen years before I saw her, but I have not been able to get any account of this operation. She had suffered from bilious attacks for ten years at almost every menstrual period; the severity of these attacks had, however, been much less for two or three years. A swelling in the abdomen was first noticed in February, 1891, and it had grown considerably before she was admitted to the Samaritan Free Hospital in the following May. At that time there was a slight yellow discolouration of the skin and conjunctivæ. In the right loin there was a solid, smooth tumour, with a rounded optline, fairly movable and not tender, extending from the costal margin to close to the pubes and beyond the edge of the rectus muscle on the left side. It stood out prominently from the rest of the abdominal surface in front. Tne growth was believed to be connected with the liver, but no detinite diagnosis was made. As it was growing rapidly an exploratory operation was performed on June $16 \mathrm{ch}$. The tamour was found to consist of a rounded swelling of the upper part of the liver, the gland being so displaced and twisted that the abnormal enlargement presented anteriorly. There was no hardness and no irregularity of outline in the growth, and, except for the alteration of shape, the surface of the organ appeared to be quite healthy. By passing the finger below the liver $I$ found that the anterior border of the gland was of normal shape, but was dirfcted downwards and slightly backwards, so that it had not been palpable before the abdomen was opened. It seemed as if the whole liver had been displaced downwards and twisted on its axis by something growing in or behind the upper and posterior part of it. I plunged a trocar and c mnnula deeply into the thickest part of the gland. The instrument appeared to pass through soft tissues of uniform consistence, and when the trocar was withdrawn nothing but blood escaped. The hanorrhage was very free, spouting a foot and a half to two feet into the air, and continuing after the cannula was withdrawn, so that I feared it might go on to a dangerous extent. It did not seem as if anything more conld be done in the way of curing the patient, and I therefore applied sponge-pressure to the puncture opening and inserted the sutures in the external wound. By the time these were in place the hæmorrbage had almost ceased, and I closed the wound without any anxiety on this point. There was no trouble during convalescence. The patient went home on Jaly 6th, the swelling continued to enlarge, and she died on Oct. 8th of the same year. There was no post-mortem examination and I did not see the patient after she went home, but, as far as I can gather, death was dne to asthenia, and no definite diagnosis was made. The operation in this case was most unsatisfactory in that no benefit resulted, and I did not even find out the

1 A paper read before the Medical Society of London, Feb. 25th, 1895. exact nature of the disease. The fact that there was no post-mortem examination leaves the case permanently an obscure one, but I think some light may be thrown on the matter by the following history. On Nov. 30th, 1894, I saw a woman thirty-eight years of age in consultation with Dr. Malcolm Mackintosh, of Claphamcommon. She was suffering from abdominal distension and pain, sickness, and frequent profuse evacuations of the bowels, the stools consisting almost entirely of watery mucus. There was some slight fever, but no jaundice and no renal or heart disease. The patient had borne three children, the third being eleven months old The symptoms, which had developed very rapidly, suggested the possibility of some pelvic mischief cansing irritation of the rectum, but after a careful examination I could find no explanation of the condition of the patient in her pelvis. The liver was very much enlarged, the anterior border of the right lobe being quite free, soft, and natural to palpation, but displaced downwards nearly as low as the anterior superior iliac spines. Owing to the distension I could not define the left lobe by palpation, but percussion showed that it also was enlarged. No definite diagnosis was made, but I thought the mischief was due to something in or behind the liver, which was pushing its lower border, and especially the right lobe, downwards. Treatment was directed to relieving the distension and supporting the strength of the patient, and sometimes the flatulence dispersed, the abdomen becoming flat, but a tendency to tympanitis continued to the last. The progress of the case continued to be very rapid, and about a week after I had seen the patient Dr. Mackintosh discovered distinct nodules on the surface of the left lobe of the liver and was able to make an exact diagnosis. The patient died a month after my visit, on Jan. 1st, 1895. After death Dr. Mackintosh obtained permission to examine the body, and found a moderately hard carcinoma, which seemed to have originated on the under surface of the liver in the region of the portal fissure. There were cancerous nodules scattered through the whole organ; but these were more numerous in the left lobe, fewer and apparently of more recent development on the right side. Dr. Mackintosh attributed the profuse discharge of mucus from the bowel to congestion of the intestine from pressure on the portal vein, a view with which I fully agree. No cancer was found in any other part of the body. There is a considerable resemblance clinically between this case and that of the patient whose abdomen I explored, as above related; and if we accept the view that pressure on the portal vein was the cause of the exhausting discharge in Dr. Mackintosh's case it is obvious that a tumour more deeply placed in the liver substance might have led to a more prolonged illness, and might have induced death without yielding any signs by which a positive diagnosis could be made during the life of the patient, as in the first case.

CASE 2. Exploration; malignant aisease of the liver.-My second exploratory operation was performed on a patient about sixty years of age, who was under the care of $\mathrm{Mr}$. Evans of Clapham-common. She had suffered from pain in the neighbourhood of the gall-bladder with liver symptoms of many years' duration, and Dr. George Harley bad seen her and had advised that an exploratory operation should be performed. When I saw the patient on Jan. 22nd, 1892, she was emaciated and intensely jaundiced. The liver edge was somewhat lower than it normally should have been, and immediately below it, in the position of the fundus of the gall-bladder, there were two very hard substances, about the size of bazel-nuts, which lay close to the abdominal wall and exhibited some mobility on each other. They felt very like two calculi in the gall-bladder. I made an incision through the abdominal wall just large enongh to admit my finger, and on examining the parts I found that the two hard substances were growths standing out from the lower surface of the liver close to its anterior border, and that there were many nodules scattered over this surface as far as my finger could reach. The upper surface showed no irregularity of ontline. The gall-bladder was not distended. As the disease was eviden tly malignant $I$ at once sewed up the wound. The operation gave rise to little disturbance and the incision healed without tronble, but the patient became gradually weaker and died of asthenia on March 5th, six weeks and a day after the operation. When I had examined the parts with my finger inside the abdomen in this case I at once observed that calculi in a gall-bladder could not have remained in position close behind the abdominal wall withont being fixed in some way, and there had been no 
evidence of distension of the gall-bladder or of any condition that would place and firmly hold two calculi fixed in the fundus.

CASH 3 Exploration; malignant disease of the panereas and duodenum.-A third case on which I operated may be regarded as one of exploration of the gall-ducts. The patient had intense jaundice and a large ovarian tumour which prevented any satisfactory examination of the hepatic region. I removed an apparently simple ovarian cystoma, and found that the patient had also a malignant growth of the pancreas. There was no tronble from the operation, but the patient died five weeks after from asthenia, and at the necropsy it was found that the pancreatic tumour involved the descending portion of the duodenum, which was converted into a tabe of cancerous tissue so thin in parts that it appeared to be jast on the point of bursting. (The case is fally reported in THE LANCET of Sept. 8th, 1894.)

CASE 4. Three operations for hydatids of liver and of sub. peritoneal connective tissue.-My first case of hydatids was gent to the Samaritan Free Hospital in November, 1890, by Mr. Starling of Charlton. The patient, who was then thirtythree years of age, complained of having "lumps" in the upper part of her abdomen, and said that she had suffered from crampy pains in the bowels from time to time for sixteen years. These pains had become more frequent and more severe, and she had first noticed the tumours when she was carrying a child that was born two years before I saw her; bat two years before that time Mr. Power of East Indiaroad, who attended her in her first confinement, told her that she had a tumour, for which he recommended her to seek treatment in some hospital. On examination I found an oval mass at the back of the abdominal cavity a little below the position of the left kidney, somewhat movable, bat too small and deeply placed to allow of an opinion being formed as to the presence or absence of fluctuation in it. A little to the right of the normal position of the gall-bladder there was another tumour, rather larger than the first, attached to the lower surface of the liver and distinctly fluctuating. After the patient had been under observation for some weeks a third tumour was discovered a little to the left of the middle line and fixed to the lower edge of the liver by a band-like attachment about half an inch long. All these swellings rapidly increased in sine, and in Febraary, 1891, the left one was rather larger than a healthy kidney; the right was nearly round and measured four inches in diameter. On percussion it exhibited the peculiar thrill of a hydatid cyst. The more central growth measured about two inches and a half from above downwards and about two inches across. The liver dulness began at the level of the nipple above. Immediately below this point an absolutely dall note was elicited for nine inches, as far as the lower border of the largest swelling, the patient being rather a small woman. To the right and left of this swelling the liver dulness was lower than normal, but the note was resonant over the two smaller tumours. The whole abdomen was slightly distended. At the back the liver dulness was absolnte for one inch and a half above the border of the ribs on the left side, and the upper border of the dull area as it crossed over to the right passed gently upwards and round to the nipple line in front. The aterus was anteflexed, and there was gome endometritis. I thought I could feel both ovaries, of about the usual size and in their proper positions, bat somewhat tender to palpation. The patient said she weldom had any cough or expectoration. At the right apex there were some crepitations heard on auscultation, but ntherwise the lungs were normal. The apex beat of the heart was displaced up wards and to the left, but the cardiac ounds were normal, and the pulse was fairly strong, beating 84 to the minute. The action of the bowels required to be assisted by medicine and the patient was thin and losing flesh, but except for the conditions related she seemed to $b_{3} a$ hoalthy woman. The kidney action was good. There was nothing in the patient's history to show how she had become infected by hydatids; she had lived in Woolwich wll her life, and said she had never had anything to do with dogs or animals of any kind. Her husband was a waterman.

I operated on Feb. 17th, 1891, making an incision in the middle line of the upper part of the abdomen. After exploring the parts I first removed the growth from the left Join. It lay in the connective tissue behind the peritoneum, It connexions baing easily separated except posteriorly, where they were more dense and much more vascular, so that numerous ressels required to be ligatured, although I did not tie them until the end of the operation in the hope that pressure by forceps might arrest the bleeding. I attempted to remove the cyst unopened, bat I had to use a good deal of force, and it unfortunately burst. There was little of the contents spilled over the peritoneum, however, becanse the sac was ruptured by considerable pressure, and the flaid was in great measure, if not entirely, discharged outwards. The tumour consisted of a single sac, having the characteristio lining of membranous tissue formed by the parasite surrounded by the asual adventitious fibrous capsale developed by the host. It contained no daughter cysts. I next took out the smaller of the cysts below the liver. It seemed to be outside this organ, but connected with it by a kind of pedicle, which I tied as I would tie the attachment of an ovarian tumour. This hydatid contained danghter cysts. The largest of the tumours was in the liver substance. I cut into it and removed much flaid and numerous daughter cysts, taking great care to keep the peritoneum clean by means of sponges packed round the opening. When I had removed most of the contents of this cavity I again explored the abdomen and found that there was a chain of hydatids running backwards along the lower surface of the left lobe of the liver. Some of these I enucleated, but the manipulation became more difficnlt as I had to follow the cysts deeper, and when the patient had been about three hours on the table I felt compelled to desist from further attempts. It was obvious that there were more cysts in various parts of the peritoneum, and that there were other cysts in the liver substance. A very long time would have been necessary to deal with them all, and the patient's condition did not warrant a continuance of the operation. I war, however, able to separate two of the chain of hydatids at which I was working without opening either of them. I washed out the empty cyst cavity in the liver with iodine and water, sewed its opening to the opening in the abdominal wall so as to make a sinus, and closed the rest of the incision in the usual way. Two drainage-tubes were passed through the sinus into the cavity, and the wound was dressed with a large quantity of carbolic gauze. The patient was on the operating table nearly three hours and a quarter. She quickly recovered from the chloroform, and convalescence took place without causing any serious anxiety. The temperature rose to $103.6^{\circ} \mathrm{F}$. in the vagina and the pulse to 120 twenty-four hours after the operation. The temperature then fell and fluctuated between $99.6^{\circ}$ and $101^{\circ}$ for three weeks, after which time it was below $100^{\circ}$ and the pulse was below 90. There was some difficulty with the bowels during the first nine days; but afterwards they moved freely, and the patient then had only to contend with the weakness natural after such an operation and with some bronchitis. The discharge from the wound was never very copious, but the incision did not completely heal for nearly three months, although long before this the patient had gained strength and put on flesh, and was able to get about freely. She left the hospital in the eleventh week after the operation. She remained under my observation, and soon after she went home the upper part of the right side of the abdomen began to enlarge again, and there was much colicky pain in the abdomen, especially after food. The bowels still required to be assisted by lazatives, but they acted better than before the operation. Menstruation was regular.

The patient was readmitted to hospital on Nov. 20th, 1891, nine months after the first operation. The right costal margin was then much more prominent than the left, the greatest measurement from the epine to the middle line in front being seventeen and $a$ half inches on the right side and sixteen inches at the same level on the left. The scar was very wide at the part where the tubes had been, and was dragged considerably to the right of the middle line. To the left of the scar, and close to the costal margin, there was a rounded swelling measuring about two and a half inches across and standing about an inch ont from the surface of the abdomen. To the right there was a large, smooth, rounded swelling reaching well down towards the pelvis and filling the whole of the right side. These swellings exhibited the thrill on percussion that is characteristic of hydatids ; they were evidently in, or closely connected to, the liver and they were dull on percussion except at their lower margins, which were rounded and partially overlapped by the intestines. Above the costal margin the percussion note was absolutely dull as high as the level of the nipple in front, and was impaired up to 
the second intercostal space on the right side. The absolute dulness behind was bounded above by a line crossing the middle line at the level of the spine of the sixth dorsal vertebra, and gradually curving downwards on the left. The lungs were very greatly compressed, and there was considerable cyanosis, but I detected no signs of active lung disease, and although there was a slight cough there was no expectoration. The heart's action was fairly good, the pulse usually beating 72 times to the minute. The apex beat was felt six and a half inches from the middle line in the fifth interspace. The temperature was normal or subnormal. In the right side of the pelvis a small tumour was felt by bimanual examination, exactly resembling an ovarian tumour and about the size of an orange. On Dec. Znd I carefully opened the abdomen by removing the old scar. After freeing some omental adhesions $I$ exposed the smaller and more prominent cyst. This I aspirated, laid open, and cleared out in the same way as I had treated the liver cyst at the first operation. It contained numerous daughter cysts. When all was clear I made a careful examination of the abdomen and found a number of small tumours low down in the pelvis. I counted five. Leaving them I returned to the liver and cut into the large cyst on its inner side, where it bulged into the one already opened. A very great quantity of fluid and daughter cysts was removed, but the bulk was not measured, as much of it was caught in towels and thrown aside. The size of this cavity may be estimated by the fact that after it was partially collapsed my sponge forceps, which measure eight and a half inches beyond the handles, did not reach a large part of the upper and posterior boundaries of the sac. It was with much difficulty that I got the parasitic sac of the main hydatid cyst away. This was very thick and firm, and would not fold up sufficiently to come through the opening until I had many times seized it and brought away small pieces. At last I succeeded in removing the bulk of it in one mass, but many small pieces were afterwards washed away with iodine and water. When the cyst was thas partially c'ezred the patient was so blue and collapsed that it was out of the question to attempt to remove the other tumours. I therefore sewed the opening in the liver to that in the abdominal wall, and closed the incision, draining the liver cavity and dressing the wound as at the first operation. This second operation lasted an hour and a half. The temperature rose to $102^{\circ}$ on the day following the operation and again on the fifth day, the pulse on the first of these occasions being 120 and on the second 96. The respirations were not connted above 32 to the minute. There was an occasional cough and considerable dyspncea, but very little expectoration, or other evidence of bronchitis. The lung resonance quickly increased, and there was marked tenderness on percussion over the upper surface of the liver for some days. The cyanosis and breathlessness disappeared very gradually, and the feebleness, which was extreme for more than a fortnight, was also slowly recovered from. The bowels again gave a good deal of trouble for a little more than a week, but when they acted freely the patient gained strength more quickly. The discharge from the liver was very profuse, and at times it contained a great deal of bile. Hydatid membranes escaped in considerable quantity at first, and later at intervals, the last observed coming away on Feb. 13th, 1892, two months and eleven days after the operation. On the twenty-fifth day the drainage-tubes, which had already been considerably shortened, were taken out and cleaned. The longest measured ten inches. They were gradually shortened, and on Jan. 20th one tube was removed. On March 18th there was only one small tube remaining, which measured two and $a$ half inches in length. On March 3rd the patient was allowed to get $u p$, but the wound was still discharging a large quantity of fluid, which was now of a thin, serous character. She went home on April 2nd, four and a half months after the operation. The wound continued to discharge very freely till about Christmas, 1892. About the beginning of December the quantity of discharge began to diminish and the wound healed very quickly and has given no trouble since; it had been open over thirteen months. When the wound healed the patient was about three months advanced in pregnancy, and I am inclined to think that the upward pressure caused by the enlarging uterus facilitated the healing of the wound. After the patient went home she had much colicky pain in the abdomen, but she said she felt better while carrying her last child than in either of her other pregnancies. After the child was born the patient became weaker and thinner and had more pain, and on examination from time to time it was evident that the pelvic tumours were increasing in size.

The patient was readmitted on March 6th, 1894. At this time, except for the presence of the cicatrix, the abdomen was quite normal on inspection, but on palpation I mapped out three very tender rounded swellings in the right side, the lowest being close to the pelvis; the highest was the largest and was the size of a small orange The whole abdomen was resonant on percussion and the liver dulness began at the level of the fifth rib and ceased a little above the costal margin below. By combined vaginal and abdominal examination I found that there were several cysts in the pelvis, but I was not able to say how many. The lungs were resonant everywhere, but the respiratory sounds were not nearly so free on the right side as on the left, and the patient now frequently suffered from bronchitis. On March 12th, two years and three months after the second operation, I again opened the abdomen, making the incision on this occasion below the umbilicas. The three tumours in the right loin and four in the pelvis were brought out and enucleated. Each consisted of a bydatid membrane, containing very little fluid, but full of collapsed dangbter cysts and enveloped in an adventitious fibrous capsule. They were attached to subperitoneal connective tissue and to neighbouring structures. A fifth cyst in the pelvis was so closely connected with the back of the cervix ateri that I cleaned it out and drained it as I had treated the sacs in the liver. The cysts removed varied in size from that of a large orange to that of a dnck's egg. Before closing the wound I examined the lower surface of the liver and found some more hydatids under the left lobe, evidently the remains of the chain I had felt at the first operation, but they had considerably enlarged. It was impossible to manipulate these throngh the incision already made, and I therefore cut direetly down on them by a vertical incision a little to the left of the middle line and close to the ribs. Three hydatids were removed from close to the lower surface of the liver, two being about the size of duck's eggs and one the size of a sparrow's egg. The liver seemeā to be of fairly normal shape and freely movable, having only loose adhesions to the scar, the upper end of which was considerably below the lower edge of the liver. Through these loose adhesions I felt a hard nodule which I thought was another small hydatid, but it was enveloped in adherent omentum, and as the operation was already a long one I thought it unwise to begin what might be a very troablesome and prolonged enucleation. This operation lasted over three hours, but it was not such a severe proceeding as either of the other two, and the patient was not so ill afterwards. During convalescence the highest temperature was $100.8^{\circ} \mathrm{F}$. on the fourth day, and the highest palse was 96 on the second day. The patient was almost free from fever and practically well after ten days, but there was a discharging sinus till June, when the wound finally healed. On leaving the hospital early in June the patient went to a convalescent home for a few weeks, and was very well while there; but after going to her own home she was for long troubled by $\approx$ cough, sometimes accompanied by considerable expectoration. On Oct. 25th she came to see me on account of a small hernia at the lower end of the incision below the umbilicas. This had been noticed for five weeks, and was no doubt due to the persistent congh. The lungs were not dull on percassion anywhere, but the liver dulness was somewhat higher than it should have been on the right side posteriorly, and the respiratory murmur was evergwhere very feeble. There were very few crepitations or râles, and at this time there was little expectoration.

I again saw the patient on Feb. 21st, 1895. She then complained of severe pains in the region of the liver, which had continued for about seven weeks and were very bad during the prolonged frost, but had been rather better since the weather became milder. On examination I found the abdomen quite flat; the incisions measured $3 \frac{1}{2}$ in., 3 in., and $2 \frac{1}{4}$ in. respectively, in the order in which they were made. The patient's cough had been much less frequent, and the hernia, which had been supported by a pad, was smaller and cansed little trouble. The liver near the middle line was very tender to percussion and palpation. Through the scar of the second operation I could feel a hard nodule about the size of a bean, which seemed to be the chief seat of tenderness, and I have no doubt this was the hard substance I had felt at the end of the last operation. The liver seemed to be smaller than normal in front, but its dull area extended rather higher than usual behind. The lungs had 
greatly improved, and, except at the right base behind, the air everywhere entered them freely. Since the severe pain in the liver region began some eight weeks previously the patient said she had lost flesh and she was very thin. It seemed as if some cyst were developing in or below the liver. I hope to keep the patient under observation, and if there is any further development I trust that I may be permitted to communicate"the sequel.

(To be continued.)

\section{THE PHYSICS OF CARDIAC SOUNDS AND MURMURS.}

BY JAMES T. R. DAVISON, M.D. EDIN.,

FORMERLY RESIDENT"PHYSTCLAN TO THE EDINBURGH ROYAL INFIRMARY.

MoRe than twenty years ago Dr. Walshe wrote ${ }^{2}$ that " the difficulty of unravelling the mechanism of the normal sounds of the heart is broadly and emphatically proved by the fact that from the time of Laennec to the present day some fiveand-thirty theories, more or less completely differing from ach other, have been proposed in its explanation." Daring these last twenty years the problem has still remained ansatisfactorily solved. I propose in the course of this paper to relate a few simple experiments which bear on the sabject, and which appear to throw a great deal of light not only on the mechanism of cardiac sounds, but likewise on that of cardiac murmurs, and which, moreover, have the adrantage from their great simplicity to be within everybody's reach. It will be advisable to study first the second sound. If after excision of the heart the aorta be firmly ligatured at a short distance from the semilunar valves, and the left ventricle having been opened, a stream of water be forcibly driven by means of an indiarabber syringe into the aorta from the ventricle, then the following takes place: the aorta becomes distended with liquid, and in the height of its distension the semilunar valves close in and shut the ventriculo-aortic orifice so that not a drop of water escapes back into the ventricle. From the ventricular side the valves are thus seen stretched by the fluid contained within the aorta. The semilnnar valves have thus been shut by a forcible injection of liquid directed from the ventricle towards the aorta. In this experiment the ligature of the aorta is made to represent the resistance offered by the column of blood in the living subject; the stream of water injected forcibly into the aorta takes the place of the ventricular contents that normally pass into the vessel with each ventricular contraction; and, lastly, the indiarubber syringe is made to represent the ventricle. How is this closure of the semilunar valves brought about?

Physiologists hold that the semilunar valves are "probably closed almost immediately after the escape of the ventricular contents," 2 and assign this closure to the refluxes produced by the negative pressure of the mere movement of the column of blood and by the elastic recoil of the arterial wall. Now, in the experiment just referred to the "negative pressure of the mere movement of the column of blood "cannot be a factor of the closure of the valves, for the simple reason that the ligature of the aorta prevents any such movement taking place. That the closure of the semilunar valve is likewise completely independent of the elastic recoil of the arterial wall the following modifications of the above experiment will plainly show. Let a part of the aorta together with the rim of the ventricle near the aortic orifice be dissected out; let a piece of linen be now sewn round the aorta from the level at which the extremities of the valves are attached to the wall of the ressel ontwards, sufficiently close to prevent distension of the artery, but not too tight to occlude its lumen; if now, after ligaturing the vessel, water be forcibly driven into the aorta from the ventricular side the vessel fills with fluid and the semilunar Palves close the orifice. Here no recoil of the arterial wall can come into play, inasmuch as its distension is prevented by the linen sewn round $i t$, yet the valves close and shat the orifice. Again, if the aorta be ligatured as before, some distance beyond the orifice, and, the ventricle having

1 Dr. Walshe: Diseases of the Heart, p. 51. 2 Text-book of Physiology (Foster), p. 246. been opened, a column of air is forcibly driven into the aorta from the ventricle by means of a gum elastic syringe, the following takes place: the vessel dilates somewhat, and the valves not only close in perfectly well, but even bulge prominently backwards towards the ventricle. Here, once more, no recoil of the arterial wall can explain the closure of the valves, as in order to produce this effect it is not necessary to drive the column of air too forcibly into the aorta so as to produce marked distension of the wall. The closure of the semilunar valves can thus be brought about irrespective of the refluxes produced either by the recoil of the arterial wall or by the negative pressure due to the mere movement of the column of blood. How, then, is this closure effected? The circumference of the aorta at the level of insertion of the extremities of the semilunar valves may be divided for purposes of description into three equal parts, the points of division corresponding to the points of insertion. If direct lines be drawn across these points of insertion an equilateral triangle will be described within the circumference of the aorta, the sides of the triangle corresponding to the loose edges of the semilunar valves. This is at once made apparent if, a part of the aorta having been dissected out together with the rim of the ventricle surrounding the orifice, dilatation of the vessel be effected by means of the fingers from both sides of the orifice at the same time. It is then seen that in the dilated state of the vessel a triangular lumen occupies the centre, and the space between the sides of the triangle and the circumference of the ressel is occupied by the somewhat lax semilunar valves. It is likewise to be observed that the edges of the valves in their lax condition dip downwards concavely between their extremities disclosing the aortic wall, which at this level is thinner and encloses a wider lumen than at the level of insertion of the extremities of the valves and upwards. When, therefore, water is forcibly injected into the ligatured aorta from the ventricle the wall of the vessel becomes distended ; this distension, per se, by separating from each other the extremities of insertion of the valves, causes the edges of these to assume collectively the sides of an equilateral triangle, the interior of which forms the lumen of the vessel at its orifice, a space occupied by valvular surface being left between the sides of the triangle and the distended wall of the vessel. Now, according to Pascal's law, pressure exerted anywhere upon a mass of liquid is transmitted undiminished in all directions and acts with the same force on all equal surfaces and in a direction at right angles to their surfaces. Therefore, the same amount of liquid pressure that, acting at right angles to the wall of the aorta, produces its distension will also act at right angles to the exposed valvular surfaces which extend from the sides of the triangle to the circumference of the vessel, this exposure of valvalar surfaces being due, as just stated, to the distension of the aorta. The liquid pressure on this exposed valvalar surface will bring about the stretching of the valves; and this stretching of the valves in its turn forces them to adopt the pouch-like form which they owe to the concavity of their bases of attachment. The liquid pressure which is being transmitted equally in all directions tends to separate these pouches more and more from the sinuses of Valsalva, this separation from the sinuses causing the pouches to approximate each other, until at last they touch and close the orifice. But this approximation of the valves being due to. their separation from the circumference of the vessel, and this separation being in its turn due to the fluid pressure which is being exercised in all directions by the water which is entering the aorta from the ventricle, it follows that the closure of the semilunar valves is effected solely by the injection of water into the aorta. During the height of the distension outwards of the aortic wall, does the distension inwards and backwards of the valves take place, both being effected by the same liquid pressure? The distension inwards and backwards of the valves being effected by the column of water entering the aorta, it is clear that this column (in its latter part) as it enters the aorta by this very act is closing the orifice against itself. When the last drop has passed the orifice the valves firmly close upon each other, this last drop being the end of that column of water which directly produces the closure of the valves. In that modification of the experiment, where the sewing of a piece of linen into and around the wall of the vessel from the level of insertion of the extremities of the valves upwards prevents the distension of the aorta from that level upwards, 